Pacific Journal of Mathematics

SOME RESULTS ON NEAREST POINTS AND SUPPORT 


\title{
SOME RESULTS ON NEAREST POINTS AND SUPPORT PROPERTIES OF CONVEX SETS IN $c_{0}$
}

\author{
M. Edelstein and A. C. Thompson
}

The space $c_{0}$ is shown to contain a closed and bounded symmetric convex body such that no point of its complement has a nearest point in it. Related results involving the existence of functionals which support each member of a family of convex sets are also discussed.

1. Introduction and preliminary results. It has been shown in [3] that if $X$ is a separable conjugate Banach space (i.e., if $X=E^{*}$ where $E$ is a normed linear space and $X$ contains a countable dense set) and if $S$ is a closed, bounded set in $X$ then, for every nonnegative real number $d$, there exist $x$ in $X$ and $s_{0}$ in $S$ such that

$$
d=\left\|x-s_{0}\right\|=\inf \{\|x-s\|: s \in S\} .
$$

Further, it was shown that under the additional assumptions that the unit ball in $X$ and the weak* closed convex hull of $S$ are both strictly convex, the set of points in $X$ admitting nearest points in $S$ is weak* dense in $X$. The aim of the present paper is to define more precisely the relationship between these geometrical properties and the assumption that $X$ is a separable conjugate space. The paper is concerned, for the most part, with the behaviour of $c_{0}$ in this respect. As is well known, this space is separable but not a conjugate space.

Our results show, first of all, that $c_{0}$ belongs to the class $\mathrm{N}_{2}$ ([4]), i.e., the class of those Banach spaces which contain a closed, bounded convex set such that no point in its complement has a nearest point in the set; thus correcting an oversight of Klee. In the third section extensions of this result are presented in two directions. Finally, it is shown that, in a certain sense, the geometry of $c_{0}$ on the one hand and that of separable conjugate spaces on the other, are diametrically opposed; here we are indebted to V. L. Klee for remarks (in a private communication) which led us in this direction.

We have tried to obtain results (one way or the other) about $m$ - a conjugate, nonseparable space-but have so far failed.

Before coming to the main theorem we give a preliminary proposition which relates various geometric properties.

Proposition 1. Let $X$ be a real normed linear space and $C$ a closed, bounded, convex set in $X$. Let $N$ denote the set of points in $X \backslash C$ which have a nearest point in $C$. Then the following are equivalent: 
(i) $N=\phi$;

(ii) if $B$ is the closed unit ball and $\lambda>0$ then $\lambda B+C$ is open; (iii) if $f \in X^{*}(f \neq 0)$ then either $f(B)$ or $f(C)$ is an open interval.

Proof. That (i) and (ii) are equivalent follows from Lemma 1 of [3]. Now if $N \neq \phi$ and $a \in N$ then, for some $\lambda>0,(\lambda B+a) \cap C$ consists of a convex, nonempty, subset $D$ of the boundary of $\lambda B+a$ so that a closed hyperplane exists which separates $\lambda B+a$ and $C$ and which contains $D$. It follows that (iii) implies (i). On the other hand, if (iii) fails, i.e., if there exists a continuous functional which attains either its infimum or its supremum on $B$ and $C$ then a simple argument involving a translation of $B$ (and possibly a reflection in the origin) produces an $a$ in $N$ (cf. also [4] p. 172) so that (i) implies (iii).

2. The space $c_{0}$ is of class $N_{2}([4])$.

THEOREM 1. There exists a closed, bounded, symmetric, convex body $S$ in $c_{0}$ such that if $f \in c_{0}^{*}(f \neq 0)$ then either $f(S)$ or $f(B)$ (where $B$ denotes the unit ball in $c_{0}$ ) is an open interval.

Proof. Let $x=\left(\xi_{1}, \xi_{2}, \xi_{3}, \cdots\right)$ denote a typical element of $c_{0}$. Consider the following linear functionals and linear operators on $c_{0}$ :

$$
\begin{aligned}
\delta_{i}(x) & =\xi_{i} \quad(i=1,2,3, \cdots) ; \\
f_{0} \in c_{0}^{*} & =l_{1} \text { defined by } f_{0}=\left(2^{-2}, 2^{-3}, 2^{-4}, \cdots, 2^{-(n+1)}, \cdots\right) ; \\
T x & =\left(\xi_{1}, \xi_{3}, \xi_{5}, \cdots, \xi_{2 n-1}, \cdots\right) ; \\
U x & =\left(\xi_{2}, \xi_{3}, \xi_{4}, \cdots, \xi_{n+1}, \cdots\right) ; \\
E x=T U x & =\left(\xi_{2}, \xi_{4}, \xi_{6}, \cdots, \xi_{2 n}, \cdots\right) ; \\
P_{i} x=U T E^{i-1} x & =\left(\xi_{k_{1}}^{i}, \xi_{k_{2}}^{i}, \xi_{k_{3}}^{i}, \cdots, \xi_{k_{n}}^{i}, \cdots\right)
\end{aligned}
$$

where

$$
k_{n}^{i}=2^{i-1}(2 n+1),(i=1,2,3, \cdots) .
$$

Let

$$
g_{i}(x)=\delta_{i}(x)+f_{0}\left(P_{i}(x)\right)
$$

and let

$$
S=\left\{x \in c_{0}|| g_{i}(x) \mid \leqq 1, i=1,2,3, \cdots\right\} .
$$

Since each $g_{i}$ is a continuous linear functional on $c_{0}, S$ is an intersection of closed half-spaces and, therefore, is closed and convex. Moreover, since $\left\|\delta_{i}\right\|=\left\|P_{i}\right\|=2\left\|f_{0}\right\|=1$, if $\|x\| \leqq z_{3}^{2}$ then $x \in S$. Also, if $\|x\|>2$, since there exists $i$ such that $\left|\xi_{i}\right|=\|x\|$, we have

$$
\left|g_{i}(x)\right| \geqq\left|\delta_{i}(x)\right|-\left|f_{0}\left(P_{i}(x)\right)\right| \geqq\|x\|-\left\|f_{0}\right\|\left\|P_{i}\right\|\|x\|=\frac{1}{2}\|x\|>1 .
$$


Thus $S$ is bounded and has nonempty interior.

It remains to show that if $f \in c_{0}^{*}$ then either $f(B)$ or $f(S)$ is an open interval. To see this, define $A^{*}$ by $A^{*} \delta_{i}=g_{i}(i=1,2,3, \cdots)$ and extend $A^{*}$ to the whole of $l_{1}=c_{0}^{*}$ by linearity and continuity. Then

$$
(A x)_{i}=\delta_{i}(A x)=g_{i}(x)
$$

so that the linear transformation $A$ on $c_{0}$ can be represented by the infinite matrix:

$$
\left(\begin{array}{lllllllllllllll}
1 & 0 & 2^{-2} & 0 & 2^{-3} & 0 & 2^{-4} & 0 & 2^{-5} & 0 & 2^{-6} & 0 & 2^{-7} & 0 & \cdots \\
0 & 1 & 0 & 0 & 0 & 2^{-2} & 0 & 0 & 0 & 2^{-3} & 0 & 0 & 0 & 2^{-4} & \cdots \\
0 & 0 & 1 & 0 & 0 & 0 & 0 & 0 & 0 & 0 & 0 & 2^{-2} & 0 & 0 & \cdots \\
0 & 0 & 0 & 1 & 0 & 0 & 0 & 0 & 0 & 0 & 0 & 0 & 0 & 0 & \cdots \\
\vdots & & & & & & & & & & & & & &
\end{array}\right)
$$

where the $i$ th row has zeros except for the set

$$
N_{i}=\{i\} \cup\left\{2^{i-1}(2 n+1) \mid n=1,2,3 \cdots\right\}
$$

and

$$
a_{i i}=1, a_{i, 2^{i-1}(2 n+1)}=2^{-(n+1)} .
$$

It is readily verified that $A$ maps $c_{0}$ onto $c_{0}$ and is one-one.

Now

$$
\begin{aligned}
S & =\left\{x \in c_{0}|| g_{i}(x) \mid \leqq 1, i=1,2,3, \cdots\right\} \\
& =\left\{x|| A_{i}^{*} \delta_{i}(x) \mid \leqq 1 \forall i\right\} \\
& =\left\{x|| \delta_{i}(A x) \mid \leqq 1 \forall i\right\} \\
& =\{x \mid A x \in B\}=A^{-1}(B) .
\end{aligned}
$$

Since $S$ is bounded this shows, incidentally, that $A$ has a bounded inverse. Also

$$
f(x)=f\left(A A^{-1} x\right)=\left(A^{*} f\right)\left(A^{-1} x\right)
$$

and so

$$
f(B)=A^{*} f\left(A^{-1}(B)\right)=A^{*} f(S) .
$$

Thus $f(B)$ is a closed interval if and only if $A^{*} f(S)$ is a closed interval. But those continuous linear functionals which attain their norm on $B$ are (finite) linear combinations of the $\delta_{i}{ }^{\prime} s$. Hence the functionals which attain their norm on $S$ are (finite) linear combinations of the $g_{i}$ 's. Since these latter functionals, as $l_{1}$ sequences, clearly have infinitely many nonzero entries it is obvious that the two sets 
are disjoint. This concludes the proof.

3. Two extensions. (i) The previous section was concerned with two sets (the unit ball $B$ and the set $S$ ) in $c_{0}$ such that the sets of nontrivial functionals which support $B$ and $S$ respectively are disjoint. Here we show that it is possible to construct a family $\mathscr{S}$, indexed by the real numbers in the interval $[0,1)$, of closed, bounded, symmetric, convex bodies in $c_{0}$ such that if $f \in c_{0}^{*}$ then $f$ attains its supremum on at most one member of $\mathscr{S}$.

Let $\alpha=0 \cdot \alpha_{1} \alpha_{2} \alpha_{3} \cdots$ be a real number in $[0,1)$ represented as a binary expansion which does not terminate in 1's, i.e., $\alpha_{n}=0$ or 1 and there are infinitely many 0 's. Let $f_{\alpha}$ be the element of $c_{0}^{*}=l_{1}$ defined by

$$
f_{\alpha}=\left(\dot{\phi}_{1}, \dot{\phi}_{2}, \cdots, \dot{\phi}_{n}, \cdots\right)
$$

where

$$
\phi_{n}= \begin{cases}2^{-(n+1)} & \text { if } \alpha_{n}=0 \\ 0 & \text { if } \alpha_{n}=1\end{cases}
$$

and let

$$
g_{i, \alpha}=\delta_{i}+P_{i}^{*} f_{\alpha} \text {. }
$$

Finally, define

$$
S_{\alpha}=\left\{x \in c_{0}|| g_{i, \alpha}(x) \mid \leqq 1, i=1,2,3, \cdots\right\} .
$$

As before $S_{\alpha}$ is a closed, bounded, convex set with interior and, as before, each $S_{\alpha}$ is supported by finite linear combinations of the functions $\left\{g_{i, \alpha} \mid i=1,2,3, \cdots\right\}$. If $\alpha \neq \alpha^{\prime}$ then, for some $n, \alpha_{n} \neq \alpha_{n}^{\prime}$ and we can suppose that $\alpha_{n}=1, \alpha_{n}^{\prime}=0$. Let $f$ support $S_{\alpha}$. Then $f$ is a finite linear combination of the $g_{i, \alpha}$. Let $i_{0}$ be the maximal index which occurs in this combination. Then the sequence representing $f$ has a zero in the $k_{0}=2^{i_{0}-1}(2 n+1)$ place. If $f^{\prime}$ supports $S_{\alpha^{\prime}}$, in order that $f^{\prime}$ have a zero in that same place either $f^{\prime}$ has no contribution from $g_{i_{0}, \alpha^{\prime}}$ or $f^{\prime}$ does have a contribution from $g_{k_{0}, \alpha^{\prime}}$. In the first case $f^{\prime}$ has zeros on the whole set

$$
N_{i_{0}}=\left\{2^{i_{0}-1}(2 k+1) \mid k=1,2,3, \cdots\right\}
$$

and therefore differs from $f$, while in the second case, since $k_{0}>i_{0}, f$ has zeros on the whole set $N_{k_{y}}$ and again $f \neq f^{\prime}$. We thus have the desired conclusion.

(ii). The set $S$ in the proof of Theorem 1 is similar to the unit ball in the sense that it is the image of the unit ball under an invertible linear transformation and hence each of its faces has finite 
codimension. We show here that it is possible to construct a set $S^{\prime}$ with the required properties and which is, moreover, strictly convex, i.e., its faces are 0-dimensional. With the same notation as in $\S 2$, let

$$
p(x)=\|x\|+\left(\sum_{n=1}^{\infty} 2^{-2 n} g_{n}(x)^{2}\right)^{1 / 2}
$$

and let $S^{\prime}=\left\{x \in c_{0} \mid p(x) \leqq 1\right\}$. Since, as can be readily seen, $p$ is a norm on $c_{0}$ which is equivalent to the original norm, $S^{\prime}$ is a centrally symmetric, convex body which is closed and bounded. Further, since $g_{n}(x)=0$ for all $n$ if and only if $x=0$ (this follows from the fact that $S$ in $\S 2$ is bounded), $S^{\prime}$ is strictly convex; (cf. Köthe [5] p. 365). To complete the proof we show that if $x$ is in the complement of $S^{\prime}$ then $x$ has no nearest point in $S^{\prime}$. Suppose, on the contrary, that there exists $x_{0}$ with $p\left(x_{0}\right)>1$ and $s_{0}$ with $p\left(s_{0}\right)=1$ such that

$$
\left\|x_{0}-s_{0}\right\|=\inf \left\{\left\|x_{0}-s\right\| \mid s \in S^{\prime}\right\} \text {. }
$$

Now, since $x_{0}, s_{0} \in c_{0}$ there exists $N$ such that

$$
\left|\delta_{j}\left(x_{0}-s_{0}\right)\right|<\frac{1}{2}\left\|x_{0}-s_{0}\right\| \text { and }\left|\delta_{j}\left(s_{0}\right)\right|<\frac{1}{2}\left\|s_{0}\right\|
$$

for all $j>N$, (clearly the numbers on the right are nonzero). Let $n=2^{i-1}(2 k+1)$. If $s_{0}=\left(\sigma_{1}, \sigma_{2}, \cdots, \sigma_{n}, \cdots\right)$, consider $s_{0}^{\prime}=\left(\sigma_{1}, \sigma_{2}, \cdots\right.$, $\left.\sigma_{n}-\varepsilon, \cdots\right)$. Clearly $g_{j}\left(s_{0}\right)=g_{j}\left(s_{0}^{\prime}\right)$ for all $j$ except $j=n$ and $j=i$. For these integers we have $g_{n}\left(s_{0}^{\prime}\right)=g_{n}\left(s_{0}\right)-\varepsilon$ and $g_{i}\left(s_{0}^{\prime}\right)=g_{i}\left(s_{0}\right)-\varepsilon 2^{-(k+1)}$. Hence

$$
2^{-2 n}\left(g_{n}\left(s_{0}^{\prime}\right)^{2}-g_{n}\left(s_{0}\right)^{2}\right)=2^{-2 n} \varepsilon^{2}-2^{-2 n} \varepsilon g_{n}\left(s_{0}\right)
$$

and

$$
2^{-2 i}\left(g_{i}\left(s_{0}^{\prime}\right)^{2}-g_{i}\left(s_{0}\right)^{2}\right)=2^{-2(i+k+1)} \varepsilon^{2}-2^{-2 i-k-1} \varepsilon g_{i}\left(s_{0}\right) \text {. }
$$

We can assume that $g_{i}\left(s_{0}\right)$ is positive (otherwise replace $\varepsilon$ by $-\varepsilon$ ). Then, since $g_{n}\left(s_{0}\right) \rightarrow 0$ as $n \rightarrow \infty$, choose $k$ so large and $\varepsilon$ sufficiently small so that
(a) $n=2^{i-1}(2 k+1)>N$
(b) $\varepsilon<\frac{1}{2}\left\|s_{0}\right\|$
(c) $\varepsilon<\frac{1}{2}\left\|x_{0}-s_{0}\right\|$
(d) $2^{-2 n+k+1} \varepsilon+2^{-2 i-k-1} \varepsilon+2^{-2 n+k+1}\left|g_{n}\left(s_{0}\right)\right|<2^{-2 i} g_{i}\left(s_{0}\right)$.

Then $p\left(s_{0}^{\prime}\right)<p\left(s_{0}\right)=1$ but $\left\|x_{0}-s_{0}^{\prime}\right\|=\left\|x_{0}-s_{0}\right\|=\inf \left\{\left\|x_{0}-s\right\| \mid s \in S\right\}$. This is clearly absurd since $x_{0}$ cannot have a nearest point which is interior to the set and the proof is complete.

4. How to support a family. It was shown in $\S 3(\mathrm{i})$ that in $c_{0}$ it is possible to construct an uncountable family of closed bounded 
convex bodies such that no linear functional supports more than one of them. In contrast we have the following theorem.

Theorem 2. Let $\left\{C_{1}, C_{2}, \cdots, C_{n} \cdots\right\}$ be a countable family of closed and bounded sets in a separable Banach space $X$ which is the conjugate of some Banach space $Y$. Let $S$ denote the set of points $y$ in $Y$ with the property that for each $i=1,2, \cdots$ there is $a c_{i} \in C_{i}$ such that

$$
\sup \left\{\langle y, c\rangle: c \in C_{i}\right\}=\left\langle y, c_{i}\right\rangle^{1} \text {. }
$$

Then $S$ is a dense $G_{\delta}$.

Proof. ${ }^{2}$ The set $S_{i}$ of all $y \in Y$ for which $\sup \left\{\langle y, c\rangle: c \in C_{i}\right\}$ is attained is, by a result of Asplund (cf. Theorem 3 and proof of Proposition 5 in [1]), a dense $G_{\delta}$. It follows that $S=\bigcap_{1}^{\infty} S_{i}$ too is a dense $G_{\hat{o}}$.

To show that countability of the family $\left\{C_{1}, C_{2}, \cdots\right\}$ in Theorem 2 is essential we bring the following

Proposition 2. To every continuous linear functional $u$ on $l_{1}$ with $\|u\|=1$ there is a closed and bounded convex set $C$ such that $u$ fails to attain its supremum on it.

Proof. It suffices to show that a $C$ as required exists for each $u=\left(u_{1}, u_{2}, \cdots\right) \in m$ for which a natural number $k$ exists with $\|u\|=$ $\left|u_{k}\right|=1$ as the unit ball may clearly serve as $C$ for all other $u$ of norm 1. Clearly, if $C$ satisfies the conclusion for a given $u$ then $-C$ does for $-u$; thus we may assume that $u_{k}=1$. Now the sequence $\left\{u_{k+1}, u_{k+2}, \cdots\right\}$ contains a subsequence $\left\{u_{n_{1}}, u_{n_{2}}, \cdots\right\}$ which is either nonincreasing or nondecreasing. The proofs being similar in both cases we assume that

$$
u_{n_{1}} \leqq u_{n_{2}} \leqq \cdots
$$

i.e., the subsequence is nondecreasing.

Let $A=\left\{x^{(1)}, x^{(2)}, \cdots\right\} \subset l_{1}$ be defined by setting

$$
x_{i}^{(m)}= \begin{cases}1-\frac{1}{m} & \text { for } i=k \\ 1 & \text { for } i=n_{m} \\ 0 & \text { otherwise }\end{cases}
$$

and set $C=\overline{\mathrm{co}} A$. Suppose there is a

${ }^{1}$ Here, and in the sequel, we find it advantageous to use the customary $\langle x, f\rangle$ for $f(x)$.

2 We are indebted to the referee for suggesting this proof. 


$$
z=\left(z_{1}, z_{2}, \cdots, z_{k-1}, z_{k}, z_{k+1}, \cdots\right) \in C
$$

at which $u$ attains its supremum. Then, as can be readily seen, $z_{1}=z_{2}=\cdots=z_{k-1}=0, \sum_{m=1}^{\infty} z_{n_{m}}=1$ and $z_{k}=1$. Since $z_{n_{M}} \neq 0$ for some natural number $M$, if $\delta=\left|z_{n_{M}}\right| / 2 M$ then $\|z-x\| \geqq \delta$ for all $x=\sum_{i=1}^{n} \lambda_{i} x^{(i)}$ with $\lambda_{i} \geqq 0$ and $\sum_{i=1}^{n} \lambda_{i}=1$. Indeed,

$$
\|z-x\| \geqq\left|z_{n_{M}}-x_{n_{M}}\right| \geqq\left|z_{n_{M}}\right|-\lambda_{n_{M}}
$$

so that we may assume that $\lambda_{n_{M}} \geqq \frac{1}{2}\left|z_{n_{M}}\right|$. But then

$$
\|z-x\| \geqq 1-\sum_{i=1}^{n}\left(1-\frac{1}{i}\right) \lambda_{i}=\sum_{i=1}^{n} \frac{\lambda_{i}}{i} \geqq \frac{\lambda_{n_{M}}}{M} \geqq \frac{\left|z_{n_{M}}\right|}{2 M}=\delta .
$$

It follows that $z \notin C$ so that $u$ cannot attain its supremum on $C$, as asserted.

5. Concluding remarks and problems.

1. We have already pointed out that the behaviour of $m$ in this respect is unknown.

2. A procedure first given by Day [2] was shown by Rainwater [6] to yield a locally uniformly convex unit ball in $c_{0}$. It is possible that a similar procedure applied to our construction of the set $S^{\prime}$ in $\S 3$ (ii) will give a locally uniformly convex set with the same properties.

3. It is unknown whether, given any closed and bounded convex body $S_{1}$ in $c_{0}$, it is possible to construct a second set $S_{2}$ such that no functional supports both $S_{1}$ and $S_{2}$ (i.e., whether Theorem 1 remains true under any equivalent renorming of $c_{0}$ ).

4. The above construction can be used in a more general $c_{0}(\Gamma)$.

5. The definition of the set $S$ in Theorem 2 can be modified so as to obtain a stronger conclusion. Indeed, without changing the proof, one can require that each element $y \in S$ strongly expose each of the sets $C_{i}$; i.e., whenever $\left\{c_{i}^{(n)}: n=1,2, \cdots\right\} \subset C_{i}$ and $\left\langle y, c_{i}^{(n)}\right\rangle \rightarrow$ $\left\langle y, c_{i}\right\rangle$ then $c_{i}^{(n)} \rightarrow c_{i}(i=1,2, \cdots)$.

\section{REFERENCES}

1. E. Asplund, Fréchet differentiability of convex functions, Acta Math., 121 (1968), 31-47.

2. M. M. Day, Strict convexity and smoothness of normed spaces, Trans. Amer. Math. Soc., 78 (1955), 516-528.

3. M. Edelstein, A note on nearest points, Quarterly J. Math., (2) 21 (1970) 403-405.

4. V. Klee, Remarks on nearest points in normed linear spaces, Proc. Colloquium on Convexity, Copenhagen, (1965), 168-176. 
5. G. Köthe, Topologische lineare Räume I, (Springer-Verlag, Berlin-Heidelberg-New York) 1966.

6. J. Rainwater, Local uniform convexity of Day's norm on $c_{0}(\Gamma)$, Proc. Amer. Math. Soc., 22 (1969), 335-339.

Received August 19, 1970. This research was supported by National Research Council of Canada Grants A-3999 and A-4066.

Dalhousie University 


\section{PACIFIC JOURNAL OF MATHEMATICS}

\section{EDITORS}

\section{H. SAMELSON}

Stanford University

Stanford, California 94305

\section{R. HOBBY}

University of Washington Seattle, Washington 98105

\section{J. DugundJI}

Department of Mathematics University of Southern California Los Angeles, California 90007

RICHARD ARENS

University of California Los Angeles, California 90024

\section{ASSOCIATE EDITORS}
E. F. BECKENBACH
B. H. Neumann
F. WoLF
K. YoSHIDA

\section{SUPPORTING INSTITUTIONS}

UNIVERSITY OF BRITISH COLUMBIA CALIFORNIA INSTITUTE OF TECHNOLOGY

UNIVERSITY OF CALIFORNIA

MONTANA STATE UNIVERSITY

UNIVERSITY OF NEVADA

NEW MEXICO STATE UNIVERSITY

OREGON STATE UNIVERSITY

UNIVERSITY OF OREGON

OSAKA UNIVERSITY

\author{
UNIVERSITY OF SOUTHERN CALIFORNIA \\ STANFORD UNIVERSITY \\ UNIVERSITY OF TOKYO \\ UNIVERSITY OF UTAH \\ WASHINGTON STATE UNIVERSITY \\ UNIVERSITY OF WASHINGTON \\ * * * * \\ AMERICAN MATHEMATICAL SOCIETY \\ NAVAL WEAPONS CENTER
}

The Supporting Institutions listed above contribute to the cost of publication of this Journal, but they are not owners or publishers and have no responsibility for its content or policies.

Mathematical papers intended for publication in the Pacific Journal of Mathematics should be in typed form or offset-reproduced, (not dittoed), double spaced with large margins. Underline Greek letters in red, German in green, and script in blue. The first paragraph or two must be capable of being used separately as a synopsis of the entire paper. The editorial "we" must not be used in the synopsis, and items of the bibliography should not be cited there unless absolutely necessary, in which case they must be identified by author and Journal, rather than by item number. Manuscripts, in duplicate if possible, may be sent to any one of the four editors. Please classify according to the scheme of Math. Rev. Index. to Vol. 39. All other communications to the editors should be addressed to the managing editor, Richard Arens, University of California, Los Angeles, California, 90024.

50 reprints are provided free for each article; additional copies may be obtained at cost in multiples of 50 .

The Pacific Journal of Mathematics is published monthly. Effective with Volume 16 the price per volume (3 numbers) is $\$ 8.00$; single issues, $\$ 3.00$. Special price for current issues to individual faculty members of supporting institutions and to individual members of the American Mathematical Society: $\$ 4.00$ per volume; single issues $\$ 1.50$. Back numbers are available.

Subscriptions, orders for back numbers, and changes of address should be sent to Pacific Journal of Mathematics, 103 Highland Boulevard, Berkeley, California, 94708.

PUBLISHED BY PACIFIC JOURNAL OF MATHEMATICS, A NON-PROFIT CORPORATION

Printed at Kokusai Bunken Insatsusha (International Academic Printing Co., Ltd.), 270, 3-chome Totsuka-cho, Shinjuku-ku, Tokyo 160, Japan. 


\section{Pacific Journal of Mathematics}

\section{Vol. 40, No. $3 \quad$ November, 1972}

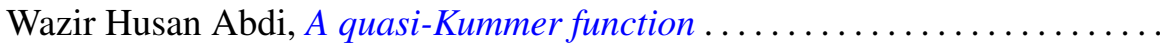

Vasily Cateforis, Minimal injective cogenerators for the class of modules of

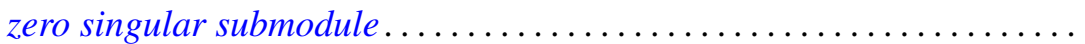

W. Wistar (William) Comfort and Anthony Wood Hager, Cardinality of

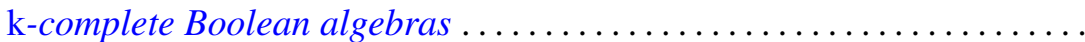

Richard Brian Darst and Gene Allen DeBoth, Norm convergence of martingales of Radon-Nikodym derivatives given a $\sigma$-lattice ..........

M. Edelstein and Anthony Charles Thompson, Some results on nearest points and support properties of convex sets in $c_{0} \ldots \ldots \ldots \ldots \ldots$

Richard Goodrick, Two bridge knots are alternating knots .

Jean-Pierre Gossez and Enrique José Lami Dozo, Some geometric properties related to the fixed point theory for nonexpansive mappings ..........

Dang Xuan Hong, Covering relations among lattice varieties .............

Carl Groos Jockusch, Jr. and Robert Irving Soare, Degrees of members of $\Pi_{1}^{0}$

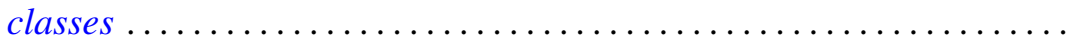

565

575

605

Leroy Milton Kelly and R. Rottenberg, Simple points in pseudoline

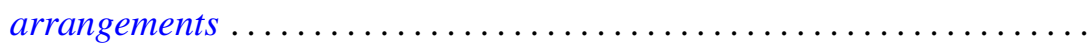

Joe Eckley Kirk, Jr., The uniformizing function for a class of Riemann surfaces....

Glenn Richard Luecke, Operators satisfying condition $\left(G_{1}\right)$ locally ... 629

T. S. Motzkin, On L $(S)$-tuples and l-pairs of matrices ... . .

Charles Estep Murley, The classification of certain classes of torsion free

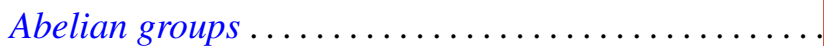

Louis D. Nel, Lattices of lower semi-continuous functions and associated topological spaces.

David Emroy Penney, II, Establishing isomorphism between tame prime

knots in $E^{3}$. . .

Daniel Rider, Functions which operate on $\mathscr{F} L_{p}(T), 1<p<2$

Thomas Stephen Shores, Injective modules over duo rings ...

Stephen Simons, A convergence theorem with boundary. .

703

Stephen Simons, Maximinimax, minimax, and antiminimax theorems and a

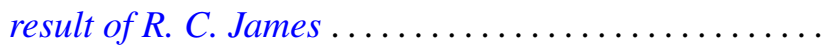

Stephen Simons, On Ptak's combinatorial lemma ........

Stuart A. Steinberg, Finitely-valued $f$-modules............

Pui-kei Wong, Integral inequalities of Wirtinger-type and fourth-order

elliptic differential inequalities .

Yen-Yi Wu, Completions of Boolean algebras with partially additive

operators ..................................

Phillip Lee Zenor, On spaces with regular $G_{\delta}$-diagonals . . . 